\title{
Prevalence of type 2 diabetes mellitus among people attending medical camps in South Chennai, India
}

\author{
S. Anusuya G. ${ }^{1 *}$, Gopalakrishnan S. ${ }^{2}$, Ravi R. ${ }^{3}$, Stephen T. ${ }^{4}$, Krishnakumar J. ${ }^{5}$, Ezhil R. ${ }^{6}$, Raja S. ${ }^{7}$, \\ Yogaraj A. ${ }^{8}$
}

DOI: https://doi.org/10.17511/ijphr.2015.i4.02

1* Ganesh S. Anusuya, Assistant Professor, Department of Community Medicine, Sree Balaji Medical College and Hospital (SBMCH ), Chennai, Tamil Nadu, India.

2 Gopalakrishnan S, Professor \& HOD, Department of Community Medicine, SBMCH, Bharath University, Chennai, Tamil Nadu, India.

3 Rama Ravi, Assistant Professor, Department of Community Medicine, SBMCH, Bharath University, Chennai, Tamil Nadu, India.

${ }^{4}$ Stephen T, Associate Professor, Department of Community Medicine, SBMCH, Bharath University, Chennai, Tamil Nadu, India.

${ }^{5}$ Krishnakumar J, Professor, Department of Community Medicine, SBMCH, Bharath University, Chennai, Tamil Nadu, India.

6 Ezhil R, Technical Officer, National Institute of Epidemiology, Chennai, Tamil Nadu, India.

7 Raja S, Assistant Professor, Department of Community Medicine, SBMCH, Bharath University, Chennai, Tamil Nadu, India.

${ }^{8}$ Arunkumar Yogaraj, Assistant Professor, Department of Community Medicine, SBMCH, Bharath University, Chennai, Tamil Nadu, India.

Background: As per the International Diabetes Federation (2013), nearly 65.1 million people were living in India with diabetes. Aim and Objectives: To estimate the prevalence of Type 2 diabetes and to compare the prevalence in relation to gender, age and area. Methodology: A cross- sectional record based study done on 1056 people attending medical camps conducted by Sree Balaji Medical College and Hospital, in various locations of South Chennai. The data regarding Random Blood Sugar (RBS), age, gender and camp site were collected from the camp register (October 2014 to June 2015). Results: Among study population, 453 (42.9\%) were males and 603 (57.1\%) females. The overall prevalence of diabetes was $11.8 \%$. Tambaram area showed highest prevalence of $27.3 \%$. Prevalence in males $(12.4 \%)$ versus females $(11.4 \%)$ [p- 0.647$]$, above 45 years $(12.6 \%)$ versus below 45 years $(10.4 \%)$ [p- 0.303], and urban (13.2\%) versus rural (11\%) [p- 0.291]. Conclusions: Prevalence of diabetes was $11.8 \%$ which is higher than the existing documented prevalence of $10.4 \%$. Hence more awareness creation and preventive measures needs to be targeted in this population to reduce the disease burden.

Keywords: Type 2 Diabetes Mellitus, Prevalence, South Chennai, RBS, Age

Corresponding Author

Ganesh S. Anusuya, Assistant Professor, Department of Community Medicine, Sree Balaji Medical College and Hospital (SBMCH ), Chennai, Tamil Nadu, India. Email: drgany2015@gmail.com
How to Cite this Article To Browse

Anusuya GS, Gopalakrishnan S, Ravi R, Stephen T, Krishnakumar J, Ezhil R, Raja S, Yogaraj A. Prevalence of type 2 diabetes mellitus among people attending medical camps in South Chennai, India. Public Health Rev Int J Public Health Res. 2015;2(4):32-37. Available From https://publichealth.medresearch.in/index.php/ijphr/

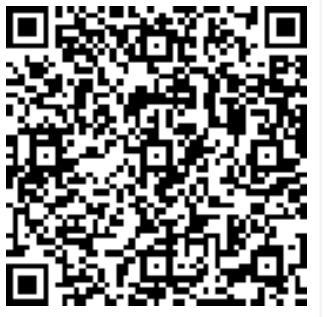
article/view/16

$\begin{array}{cc}\begin{array}{c}\text { Manuscript Received } \\ 2015-09-28\end{array} & \begin{array}{c}\text { Review Round 1 } \\ 2015-10-11\end{array} \\ \text { Conflict of Interest } \\ \text { No } & \text { Funding } \\ \text { Nil }\end{array}$

Review Round 2
2015-10-19
Ethical Approval
Yes

Review Round 3

Accepted 2015-10-30

(C) 2015 by Ganesh S. Anusuya, Gopalakrishnan S, Rama Ravi, Stephen T, Krishnakumar J, Ezhil R, Raja S, Arunkumar Yogaraj and Published by Siddharth Health Research and Social Welfare Society. This is an Open Access article licensed under a Creative Commons Attribution 4.0 International License https://creativecommons.org/licenses/by/4.0/ unported [CC BY 4.0].

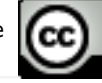

Note 


\section{Introduction}

According to the World Health Organization (WHO) the global prevalence of diabetes was estimated to be $9 \%$ among adult population as of 2014[1]. As per the International Diabetes Federation (2013), nearly 65.1 million people were living in India with diabetes [2]. More than $80 \%$ of diabetes deaths occur in low- and middle-income countries [3]. WHO projects that diabetes will be the 7th leading cause of death in 2030 [4]. The Prevalence of diabetes in Tamilnadu as per the ICMR Study done in 2011 was $10.4 \%$ [5]. The Prevalence of diabetes in chennai is always on the rise [6]. Hence we can understand that diabetes is a major public health problem and also a challenge to tackle.

\section{Aims and Objectives}

To estimate the prevalence of Type 2 diabetes (using screening test) as per Random Blood Sugar (RBS ) values $>200 \mathrm{mg} / \mathrm{dl}$ using glucometer in various parts of South Chennai among medical camp attendees. To compare the prevalence in relation to gender, age, and locations.

\section{Materials and Methods}

Type of study: Cross sectional record based study.

Period of study: October 2014 to June 2015.

Study settings: Urban and Rural areas of South Chennai patients attending medical camps conducted by Sree Balaji Medical College and Hospital(SBMCH) .Inclusion Criteria: Patient who have attended medical camps in South chennai region and have undergone a RBS check. Data Collected: RBS values, age, gender and camp site were collected from the camp register (October 2014 to June 2015). An operational definition of RBS glucometer values of $>200 \mathrm{mg} / \mathrm{dl}$ was defined as having diabetic. Descriptive analysis and Chi square test done to see the statistical significance between various parameters. Correlation regression analysis was also done to see the relationship between CBG (Capillary Blood Glucose) values and age .

Justification for using RBS values $>\mathbf{2 0 0} \mathbf{~ m g / d l}$ for diagnosing diabetes: We followed the Mayo Clinics, diagnostic criteria for diabetes as using RBS values $>200 \mathrm{mg} / \mathrm{dl}$ with any one of the clinical symptoms of diabetes like thirst and excessive urination [7].
Even WHO have mentioned RBS values greater than $200 \mathrm{mg} / \mathrm{dl}$ can be used as a screening tool for diagnosing diabetes in resource poor settings and practical consideration of the existing situations[8]. Hence this will be apt for our medical camp attendees to use RBS values as a diagnostic screening tool for diabetes detection.

Ethical Clearance: The ethical clearance was obtained from the Institutional Ethical Committee and Institutional Review board of Sree Balaji Medical College and Hospital, Chennai, India.

Sample size Calculation: By assuming a prevalence of around $12 \%$ from a previous study [9] a sample size of 1010 was estimated by using the formula, $\mathrm{n}=\mathrm{Za} 2 \mathrm{pq} / \mathrm{L} 2$ including a $10 \%$ non responders. But we finally arrived at a sample size of 1056. Sampling techniques used was convenient sampling. We took the details of the patients data from the camp register. Only camp data regarding camps conducted in Southern Chennai were included in the study.

\section{Results}

The mean age of the study population was 52 years (Range 15 to 97). Most number of study participants were females $(57.1 \%),>45$ years old $(67.1 \%)$ and belong to rural area $(62.7 \%)$. The mean Random Blood sugar values were 135.09 $\mathrm{mg} / \mathrm{dl}$. The overall prevalence of diabetes was $11.8 \%$. The baseline characteristics are shown in table 1.

Table 1: Baseline Characteristics $N=1056$

\begin{tabular}{|l|l|c|c|}
\hline \multicolumn{2}{|c|}{ Variables } & N & $\%$ \\
\hline \multirow{3}{*}{ Gender } & Male & 453 & 42.9 \\
\cline { 2 - 5 } & Female & 603 & 57.1 \\
\hline \multirow{2}{*}{ Diabetics RBS> $200 \mathrm{mg} / \mathrm{dl}$} & Diabetics & 125 & 11.8 \\
\cline { 2 - 5 } & Non Diabetics & 931 & 88.2 \\
\hline \multirow{2}{*}{ Age Categories } & Greater than 45 Years & 709 & 67.1 \\
\cline { 2 - 5 } & Less than 45 Years & 347 & 32.9 \\
\hline Place of Residence & Urban & 394 & 37.3 \\
\cline { 2 - 5 } & Rural & 662 & 62.7 \\
\hline
\end{tabular}

$\mathrm{N}=$ Numbers,$\%=$ Percentage

Comparison of Diabetic Prevalence with other variables: We compared the variables like gender, age and locality with prevalence of diabetes. The prevalence was high among males $(12.4 \%)$, age $>$ 45 years $(12.6 \%)$ and among urban population $(13.2 \%)$, but these findings were not statistically significant. The findings are shown in table 2. 
Table 2: Comparison of Diabetic Prevalence with gender, age and locality

\begin{tabular}{|l|l|l|l|l|l|}
\hline Variables & Diabetes Prevalence & Chi Square & OR & $95 \%$ CI & P-Value \\
\hline \multirow{2}{*}{ Gender } & Male $12.4 \%$ & 0.2 & 1.1 & $0.7-1.6$ & 0.647 \\
\cline { 2 - 6 } & Female $11.4 \%$ & & & & \\
\hline \multirow{2}{*}{ Age } & $>45$ years $12.6 \%$ & 1.05 & 1.2 & $0.8-1.8$ & 0.303 \\
\cline { 2 - 3 } & $<45$ years $10.4 \%$ & & & & \\
\hline \multirow{2}{*}{ Locality } & Urban $13.2 \%$ & 1.2 & 1.2 & $0.8-1.8$ & 0.291 \\
\cline { 2 - 3 } & Rural $11 \%$ & & & & \\
\hline
\end{tabular}

OR= Odds Ratio , 95\%CI = 95 Percent Confidence Interval

Prevalence of Diabetes in Various locations of South Chennai: The figure 1 shows the prevalence of diabetes in various locations of South Chennai. As you can see from the figure 1 , the prevalence was very high in Tambaram $(27.2 \%)$ followed by Pammal (21.7\%), Nelvoyal (14\%), Sanatorium $(12.7 \%)$, chromepet (12.6\%), Manimangalam (10.2\%), Nanmangalam (8.3\%), Pallavaram (7.4\%), Mudichur (6.5\%) and Nanganallor (5.5\%) .

Fig-1: Prevalence of Diabetes in various locations of South Chennai

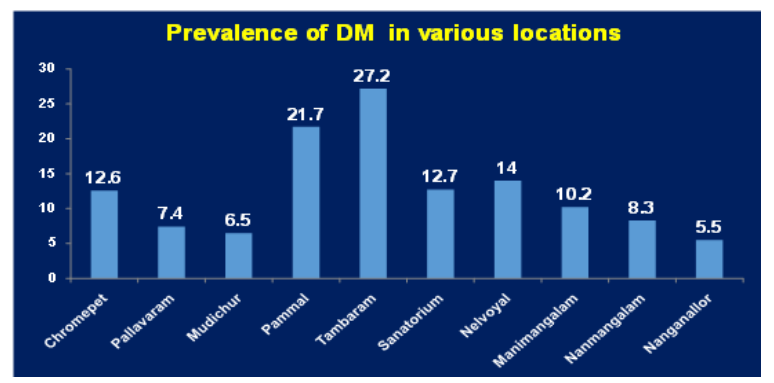

Correlation between Age and CBG Values: When we did correlation and regression analysis to see the relationship between the CBG and age, we found that there was a positive correlation between age and CBG values, showing that as the age increseases the CBG values also increases( $r-0.07$ ) [p-value < 0.05] Shown in Figure 2.

Fig-2: Correlation between age and CBG values

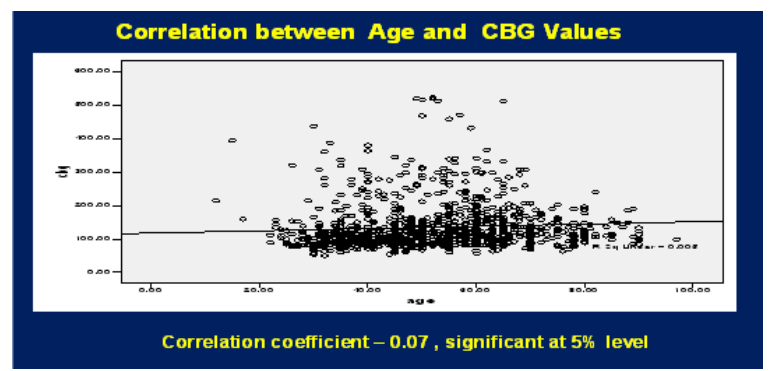

Comparison of Mean RBS with age : Our study showed that the mean RBS values in age $>45$ years were high $(141.21 \mathrm{mg} / \mathrm{dl})$ when compared with < 45 years $(122.57$ ) [ $p$-value $=0.0001]$ as shown in Figure 3.

Fig-3: Comparison of Mean RBS values with age.

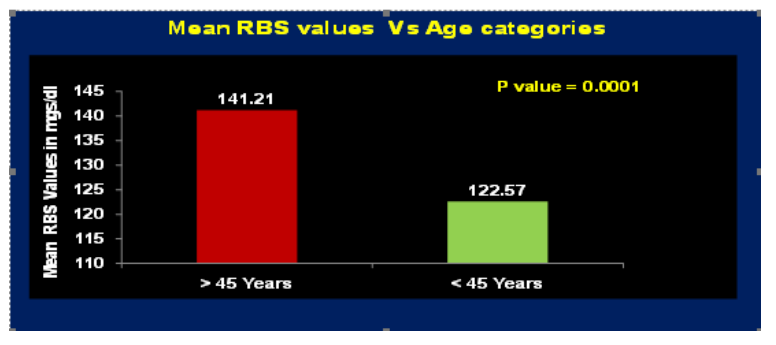

\section{Discussion}

Our study showed that the overall prevalence of diabetes in South Chennai was $11.8 \%$. This prevalence was slightly higher than the last documented prevalence of $10.4 \%$, a study done in Tamilnadu by Anjana et al [5] .We compared the prevalence of diabetes in Chennai with various other studies [5, $10-15$ ] done in Chennai and in Tamilnadu. It is clear from the table 3 there is a steady increase in the prevalence of diabetes in Chennai from 1996 to 2008 [5, 10-15]. The highest reported prevalence in chennai city was $18.6 \%$ a study done by Ramachandran et al [15]. Even our study showed there were some pocket areas showing very high prevalence, like tambaram (27.2\%) and Pammal ( $21.7 \%)$. The overall prevalence was $11.8 \%$, which was comparable with the study done by Anjana et al [5] in Tamilnadu, showing a prevalence of $10.4 \%$. The major concern in our study is that the criterion used for diagnosing diabetic was based on RBS values. Hence these cases needs to be confirmed with a fasting and post prandial blood glucose values. Hence the results should be interpreted with certain reservations. Nearly $88.2 \%$ of our study population was non diabetic as per RBS values, but still we could find a positive correlation between CBG values and increasing age. Even the mean RBS values in age group > 45 years were higher than the mean RBS values in age group < 45 years (Figure.3). A study done by Gary TC Ko et al [17] in non diabetic Hong Kong Chinese population showed a significant increase in plasma glucose levels with age. Their finding of positive correlation was related to fasting, 2-hour post-prandial, and also for random plasma glucose levels. 
Table 3: Comparison of Prevalence of Diabetes in Chennai with our study $[5,10,-15,16]$

\begin{tabular}{|l|l|l|}
\hline \multicolumn{1}{|c|}{$\begin{array}{c}\text { Year of } \\
\text { Publication }\end{array}$} & \multicolumn{1}{|c|}{ Author } & \multicolumn{1}{|c|}{ Prevalence } \\
\hline 1992 & $\begin{array}{l}\text { Ramachandran et al } \\
{[10]}\end{array}$ & $8.2 \%$ \\
\hline 1997 & $\begin{array}{l}\text { Ramachandran et al [ 11 } \\
{[11.6 \%}\end{array}$ \\
\hline 1999 & Bai et al [12 ] & $7.6 \%$ \\
\hline 2001 & Mohan et al [13 ] & $12 \%$ \\
\hline 2006 & Mohan et al [14 ] & $15.5 \%$ \\
\hline 2008 & Ramachandran et al & $18.6 \%$ \\
\hline 2011 & Anjana et al [ 5 ] & $10.4 \%$ (Tamilnadu \\
\hline $\begin{array}{l}\text { Present study } \\
(2015)\end{array}$ & Ganesh Anusuya et al & $11.8 \%$ \\
\hline
\end{tabular}

Our study has also shown a similar positive correlation between age and RBS values. The reason for positive correlation between CBG values and age may be due to the decreasing insulin sensitivity with increasing age [18-21]. We did not find any statistically significant difference in prevalence between gender, age categories ( $<45$ years vs $>45$ years ) and between rural and urban population (Table 2). Our study showed the prevalence were more among males (12.4\%) than females $(11.4 \%)$, similar findings were observed in other studies [ 22,23$]$. In our study the prevalence of diabetes were more in urban population (13.2\%) vs rural population ( $11 \%)$. Similar findings were observed in other studies done in India [10, 24 ].

\section{Limitations}

The results of our study should be interpreted with caution as the diagnostic criteria used for diagnosis of diabetes was purely based on RBS values > $200 \mathrm{mg} / \mathrm{dl}$.

\section{Conclusions and Recommendations}

Our study showed the prevalence of diabetes in Southern parts of Chennai was $11.8 \%$. As the diagnostic criterion used was purely based on RBS values, all these patients should be followed up for confirmation of diabetic status. Prevalence of $11.8 \%$ was higher than the existing documented prevalence of $10.4 \%$ [5]. Hence more awareness creation, screening and preventive measures needs to be targeted in this population to reduce the disease burden.
Also our study showed pockets of areas of very high prevalence, hence more awareness to be created and also the cause of high prevalence in those areas needs to be studied further. The positive correlation between age and RBS values shows that more life style modifications like proper diet and exercise counselling to be adviced to the population greater than 45 years old and also creating more awareness from young age can prevent them from becoming diabetic at a later age.

\section{Authors Contributions}

Dr Ganesh S.A carried out study design as well as data collection, and wrote manuscript. Dr $\mathbf{S}$. Gopalakrishnan, Dr Stephen $\mathbf{T}$, Dr Raja $\mathbf{S}$ and Dr Arunkumar Yogaraj reviewed the manuscript and approved the final version. Dr Rama $R$ and Ezhil $\mathrm{R}$ carried the statistical analysis and data management.

\section{Acknowledgements}

Our sincere thanks to the chairman, Dean and Vice Principal of Sree Balaji Medical College. Special thanks to all the staffs involved in conducting the medical camp.

\section{Reference}

01. WHO. Global status report on non communicable diseases 2014. Geneva, World Health Organization. 2012.

[Crossref]

02. IDF Diabetes Atlas. 6 th edition. Available at: [Article] [Crossref]

03. World Health Organization. Global Health Estimates- Deaths by Cause, Age, Sex and Country, 2000-2012. Geneva, WHO. 2014. [Crossref]

04. Mathers CD, Loncar D. Projections of global mortality and burden of disease from 2002 to 2030. PLoS Med. 2006 Nov;3(11)e442.

[Crossref]

05. Anjana RM, Pradeepa R, Deepa M, Datta M, Sudha $V$, et al. Prevalence of diabetes and prediabetes (impaired fasting glucose and/or impaired glucose tolerance) in urban and rural India- phase I results of the Indian Council of Medical Research-India DIABetes (ICMR-INDIA B) study. Diabetologia. 2010;54(12)3022-7. [Crossref] 
06. Mohan V, Sandeep S, Deepa R, Shah B, Varghese C. Epidemiology of type 2 diabetesIndian scenario. Indian J Med Res. 2007;125(3)217-30.

[Crossref]

\section{7. [Article] [Crossref]}

08. Screening for Type 2 Diabetes. Report of a world Health Organization and International Diabetes Federation meeting. 2003.

Available at: [Article] [Crossref]

09. Gupta M, Prabhu K, Parijatham BO, Kalaiselvi VS, Rajendran SM. Jamila Rose Prevalence of Diabetes Mellitus in South India- A Retro spective Analysis. JIMSA. 2012;25(4)239-240. [Crossref]

10. Ramachandran A, Snehalatha C, Dharmaraj D, Viswanathan $M$. Prevalence of glucose intolerance in Asian Indians, Urban-rural difference and significance of upper body adiposity. Diabetes Care. 1992;15(10)1348-55.

[Crossref]

11. Ramachandran A, Snehalatha C, Latha E, Vijay $V$, Viswanathan M. Rising prevalence of NIDDM in an urban population in India. Diabetologia. $1997 \mathrm{Feb} ; 40(2) 232-7$.

[Crossref]

12. Bai PV, Krishnaswami CV, Chellamariappan M. Prevalence and incidence of type- 2 diabetes and impaired glucose tolerance in a selected Indian urban population. J Assoc Physicians India. 1999 Nov;47(11)1060-4.

[Crossref]

13. Mohan V, Shanthirani S, Deepa R, Premalatha G, Sastry NG, Saroja R. Chennai Urban Population Study (CUPS No 4), Intra-urban differences in the prevalence of the metabolic syndrome in southern India- the Chennai Urban Population Study (CUPS No 4). Diabet Med. 2001April;18(4)280-7.

[Crossref]

14. Mohan V, Deepa M, Deepa R, Shanthirani CS, Farooq S, Ganesan A, et al. Secular trends in the prevalence of diabetes and glucose tolerance in urban South India-the Chennai Urban Rural Epidemiology Study (CURES-17). Diabetologia. 2006 Jun;49(6)1175-8.

[Crossref]
15. Ramachandran A, Mary S, Yamuna A, Murugesan N, Snehalatha C. High prevalence of diabetes and cardiovascular risk factors associated with urbanization in India. Diabetes Care. 2008 May;31(5)893-8.

[Crossref]

16. Anjana RM, Ali MK, Pradeepa R, Deepa M, Datta $M$, Unnikrishnan $R$, et al. The need for obtaining accurate nationwide estimates of diabetes prevalence in India - Rationale for a national study on diabetes. Indian J Med Res. 2011 Apr;133(4)369-380.

[Crossref]

17. Gary TC Ko , Hendena PS Wai, Joyce SF Tang. Effects of Age on Plasma Glucose Levels in Nondiabetic Hong Kong Chinese. Croat Med J. 2006 Oct;47(5)709-713.

[Crossref]

18. Stout RW. Glucose tolerance and ageing. J R Soc Med. 1994 Oct;87(10)608-9.

[Crossref]

19. Basu R, Breda E, Oberg AL, Powell CC, Dalla Man C, Basu A, et al. Mechanisms of the ageassociated deterioration in glucose tolerancecontribution of alterations in insulin secretion, action, and clearance. Diabetes. 2003 Jul;52(7)1738-48.

[Crossref]

20. Broughton DL, Taylor R. Review- deterioration of glucose tolerance with age the role of insulin resistance. Age Ageing. 1991May;20(3)221-5. [Crossref]

21. Ferrannini E, Natali A, Capaldo B, Lehtovirta M, Jacob $S$, Yki-Jarvinen $\mathrm{H}$. Insulin resistance, hyperinsulinemia, and blood pressure- role of age and obesity, European group for the study of insulin resistance (EGIR). Hypertension. 1997 Nov;30(5)1144-9.

[Crossref]

22. Vijayakumar G, Arun R, Kutty VR. High prevalence of type 2 diabetes mellitus and other metabolic disorders in rural central Kerala. J Assoc Physicians India. 2009 Aug;57;563-567. [Crossref]

23. Reshma S Patil, Jayashree S Gothankar. Prevalence OF Type-2 Diabetes Mellitus and Associated Risk Factors in an Urban Slum of pune city, India. Nat J Med Res. 2013;3(4)346349.

[Crossref] 
24. Zargar AH, Khan AK, Masoodi SR, Laway BA, Wani Al, Bashir MI,et al. Prevalence of type 2 diabetes mellitus and impaired glucose tolerance in the Kashmir Valley of the Indian subcontinent. Diabetes Res Clin Pract. 2000 Feb;47(2)135-46.

[Crossref] 